\title{
The Wingman Project: An Exploratory Study of School-Based \\ Communication with Grandparents
}

\author{
Meghan Eliason \\ Boise State University \\ United States
}

\begin{abstract}
In this paper, I explain the design and implementation of an e-newsletter created to engage grandparents with public schools. A brief literature review, the process for creating the enewsletter, and my data collection methods are explained. The conclusions and implementations offered provide insight into how public schools can engage grandparents as important members of their school communities.
\end{abstract}

\section{Introduction to the The Wingman Project}

According to Reynolds, Wright, and Beale (2003) the structure of American families is changing and "children are growing up in blended families, families with both parents working, single parent families, multigenerational families, and families headed by grandparents" (Discussion section, para. 3). Grandparents in all types of family structures have been found to have a positive influence on grandchild well-being (Sear \& Coall, 2011; Tanskanen \& Danielsbacka, 2012; Yorgason, Padilla-Walker, \& Jackson, 2011). In addition to grandparents' roles within the family structure, their engagement with schools has been documented as influential. Grandparents' roles as tutors in schools has influenced students to have more positive attitudes and ideas about older generations (Reynolds et al., 2003; Strom \& Strom, 1995; Spudich \& Spudich, 2010). These findings related to grandparents' positive influence in the schools echo the substantial and comprehensive findings of the similar positive influence of parental involvement. Mutch and Collins (2012) state, "The better the engagement between parents, families, and schools, the greater the positive impact on student learning" (p. 168).

Although there is a strong emphasis on parental involvement in both the literature and in practice, the issue of deliberately involving grandparents in the schools remains a relatively 
unstudied resource. According to Strom and Strom (1995), there are many kinds of activities that grandparents can participate in at schools. Grandparents can listen to children read, review academic content with students, provide supervision at recess or lunch, and assist teachers with tasks such as grading papers, preparing materials, etc. (Strom \& Strom, 1995). Through a review of literature I determined that school efforts to involve grandparents in the education of their own grandchildren are scarce. In this research study, a specific method of communication aimed at establishing communication between schools and grandparents of the school's current students was studied. The Wingman was a monthly e-newsletter that was distributed to grandparents via email. For the purpose of this research study, the definition of grandparents included any adult identified by the caregiver to be functioning in a traditional grandparent role and not living at the same residence of the child. This definition included biological grandparents, legal grandparents or surrogate grandparents. The focus of this study was to notice the influence of The Wingman on adults in a traditional non-custodial grandparent role. Also, both local and distant grandparents were interviewed to gain their different perspectives. Local grandparents lived within 300 miles of the school and may have had more opportunities to be physically present at the school. Distant grandparents, who lived more than 300 miles from the school, and were less likely to be physically present at the school and may have been more dependent on The Wingman for information.

In the fall of 2011, a parent volunteer at an elementary school site in Oklahoma approached the principal with the idea to start an e-newsletter that would be distributed via email to grandparents of students at the school. The school was diverse in the socio-economic status of its children, with varying levels of parental involvement; it was also faced with decreasing budgets, and conversations were ongoing within the school's parent-teacher organization about how to increase giving toward the primary educational purposes of the school. The parent proposed that through e-newsletter communications with grandparents, a deliberate expansion of the typically defined school community, the school may receive immediate help with meeting student or school needs but, perhaps more importantly, could strategically build an extended investment in the school for the future. Thus, the original impetus for the project was to create a short- and long-term economic buffer, as well as provide additional support for some children who may not have other active family members. The principal approved the effort and The Wingman was created. During this research study each of the three research sites has a similar communication method in place to provide grandparents with general communication about school news, events, and needs. The communication method in place is a monthly or quarterly e-newsletter called The Wingman. The Wingman was created by a parent volunteer and counselor at one of the sites, and it was created by the researcher and principal at the other three sites.

The name The Wingman comes from a definition obtained from U.S. Tinker Air Force Base in Midwest, OK (2011), which states: 
The term Wingman stems from a time-honored tradition within the Air Force. . that essentially says a lead pilot will never lose his or her Wingman. It's a promise, a pledge, a commitment. . . Wingman Culture affirms that each and every person is essential to our mission ("Virtual Wingman," para. 1).

This name was chosen because of the purpose of the e-newsletter, which was to enlarge the school community and provide grandparents a way to serve as an additional support network for the school and its students.

This pilot effort was shared with me in November of 2011 and revisited in depth in January of 2012. After extensive conversations regarding the operation of The Wingman and examination of documents that explained it establishment, organization, and publication process, it was decided that three additional pilot sites would be located in Oklahoma and an in-depth research study would be pursued to explore the experiences of the schools and the grandparents involved. Permission was obtained from the superintendents and principals at each of the sites, research approval was received from the Oklahoma State University IRB, and the monthly enewsletters were launched at the additional sites in September of 2012.

The students at all four schools were provided with printed invitations to submit email addresses of their grandparents and extended family members. The email addresses provided by the students and their families were used to generate the distribution list for each school. Each month The Wingman was created by the designated parties (depending upon the school) and often included pictures, quotes from individual students, special stories about events, and sometimes specific contributions from teachers or the principal. While the e-newsletter at times contained specific contributions about a featured class, the purpose of The Wingman was to serve as a general communication method and strategic tool for the school and/or principal. It was delivered to grandparents' email inboxes, but did not serve as a specific child or teacher invitation, because the communication was not personalized to the grandparent. The Wingman enewsletter was only delivered via email and was not printed and distributed to any family members by the school. The decision to refrain from printing and sending hard copies of this newsletter was made as part of the original design of The Wingman by myself and the lead administrator at each site.

\section{Study Design}

The purpose of this study was to explore the outcomes of regular written communication with grandparents of enrolled students. This study was conducted at Oklahoma public schools of varying sizes and types; data sources included teachers, staff, parents, grandparents, in loco grandparentis and other involved adults over the age of 18. Through this study, I explored how meaning was constructed through the engagement of grandparents and through interactions among grandparents and the school staff. In addition to the epistemological perspective of constructionism, the more specific theoretical perspective of social constructivism further describes the nature of this study. 
According to Creswell (1998), qualitative research can be defined as "an inquiry process of understanding based on distinct methodological traditions of inquiry that explore a social or human problem" (p. 15). The methodology for this research study was qualitative due to several characteristics of the study. First, the nature of the research questions called for a study that described what was going on in the particular settings of focus. Additionally, to fully explore the communication method employed by the schools, a detailed view of the topic needed to be presented. Finally, a qualitative study was appropriate because it allowed me to explore what individual grandparents think about their role in their grandchildren's lives. The specific design of this qualitative research study was an exploratory study of the communication method employed by the three individual pilot sites. The following two research questions allowed me to gather extensive data related to the program's effectiveness at reaching its goal of improved grandparent involvement in public schools:

1. How is school-grandparent communication influenced by the implementation of The Wingman Project in selected schools?

2. How is Hoover-Dempsey et al.'s (2005) description of motivational beliefs established in regular participants of The Wingman Project?

a. How has The Wingman Project influenced grandparent role construction in the education of their grandchildren?

b. How has The Wingman Project influenced grandparent self-efficacy to become involved in their grandchildren's education?

The use of an exploratory study embodies both the earlier mentioned broad epistemological perspective of constructionism and the theoretical perspective of social constructivism that includes the idea that individuals form meaning about objects and things through interaction with others. In the field of qualitative research, the researcher is a key instrument in the data collection process (Creswell, 1998, p. 16). The specific methodology and methods employed by the researcher must be well chosen and expertly executed, to ensure accurate findings from the study (Creswell, 1998). With this importance of researcher proficiency in mind, this study employed six specific methods of data collection for each of the three pilot sites. The six methods included: surveys, interviews, document and artifact examination, observations and field notes, informants, and school data collection.

\section{Participants}

Study participants included: (1) the school's lead administrator, describing The Wingman Project and the outcomes they observed and (2) the grandparents, describing their experiences involving The Wingman Project. Lead administrators and grandparents from each site were recruited via an email invitation to share their experiences. The email invitation explained my background and my role in conducting research at the school and included a link to a secure survey where participants shared their experiences by answering a list of questions. Initially, the email invitation was sent to all staff members at each school and to each grandparent who was 
receiving of The Wingman Project e-newsletter. The participants were recruited through multiple emails in the fall of 2013.

For each of the three pilot sites, the lead administrator for The Wingman served as a participant as well as grandparents of students who attended one of the three research sites. For the purpose of research study, the definition of grandparents included any adult identified by the caregiver to be functioning in a traditional grandparent role. This definition included biological grandparents, legal grandparents, or surrogate grandparents. The focus of this study was to notice the influence of The Wingman on adults in a traditional grandparent role. Attempts were made to interview local grandparents who lived in the same community as their grandchildren and, thus, may be involved in instances of being physically present at the school through attendance at school programs, volunteer efforts, or other activities. Distant grandparents, who lived more than 300 miles from their grandchildren, were also sought as participants for the study. Distant grandparents are generally less likely to be physically present in the school on a regular basis and thus may be more dependent on The Wingman to learn about activities and programs at the school. I selected a distance of 300 miles to classify as distant because this would make travel much more time consuming and could potentially limit the number of school functions that a grandparent could attend.

For each pilot site, I sought to secure two or three interviews with local grandparents and two or three interviews with distant grandparents. Attempts were made to interview grandparents who had been a member of The Wingman for at least six months and indicated that they read The Wingman each month. These two characteristics support purposeful sampling in regards to members who were likely to have had more experiences with the communication tool being studied. After multiple attempts to secure interviews with grandparents, a total of six participants were recruited. Four the participants were distant grandparents that lived further than 300 miles from their grandchildren and two of the participants lived near their grandchildren.

\section{Theoretical Framework}

The use of a theoretical framework provides both design guidance and another level of analysis for qualitative research. In addition to the presentation of the study's findings, applying a theoretical framework causes both the researcher and the reader to consider how the evidence either supports or provides contrary examples to a previously generated line of thought. According to Creswell (1998), "social science theories provide an explanation, a predication, and a generalization about how the world operates" (p. 84) and can be applied either before, during, or after data collection has taken place for the study. Theoretical analysis for this research study was selected $a$ priori and was used as an influencer on the design of the study, methods, and data collection processes as well as a lens through which to evaluate the data. The theoretical analysis was used from design through analysis.

Two popular theoretical frameworks are often referred to in research regarding parental involvement in public education. The frameworks are Epstein and VanVoorhis's (2010) work, 
which focuses on overlapping spheres of influence and six specific types of parental involvement, and Hoover-Dempsey and Sandler's (1995, 1997, 2005) work, which focuses on explaining the motivation for and process of parental involvement (Hoover-Dempsey \& Sandler, 1997; Walker, Wilkins, Dallaire, Sandler, \& Hoover-Dempsey, 2005). This study uses the Hoover-Dempsey and Sandler revised model (2005), which provided a greater structure for recognizing the sociological factors, motivational forces, and influences that grandparents have on students' learning and well-being.

\section{History of Theoretical Framework}

In 1992, Hoover-Dempsey, Bassler, and Brissie examined the connection between parents' sense of efficacy and its relationship to parent involvement. The basis for their examination was an understanding and application of Bandura's work on personal efficacy, which encompasses the idea that "one is capable of achieving specific outcomes on behavior choices" (Hoover-Dempsey et al., 1992). In essence, Hoover-Dempsey et al. wanted to see if Bandura's work on self-efficacy would also hold true in the relationship between parents and school involvement. By applying Bandura's theory, Hoover-Dempsey et al. hypothesized that parents hold personal efficacy beliefs about their abilities to help their children with the schooling and learning process (1992). In turn, these beliefs will influence parents' decisions and determination to be involved with their child's school. This original study found that parents' personal efficacy did appear to facilitate increased school involvement in some areas (Hoover-Dempsey et al., 1992).

The completion of this initial study by Hoover-Dempsey, Bassler, and Brissie led Hoover-Dempsey and Sandler to create a model of the parental involvement process that was originally published in 1995. An additional, modified description of the model from a 1997 publication by Hoover-Dempsey and Sandler was also reviewed for this study. This version of the model includes five distinct levels that identify and explain various components of parent involvement (Figure 1).

Figure 1. Hoover-Dempsey and Sandler Model of the Parental Involvement Process (1995, 1997)

Level 5

\begin{tabular}{|l|l|}
\hline \multicolumn{2}{|l|}{ Child/student outcomes } \\
\hline Skills \& knowledge & $\begin{array}{l}\text { Personal sense of efficacy for doing well in } \\
\text { school }\end{array}$ \\
\hline
\end{tabular}

Level 4

Tempering/mediating variables 


\begin{tabular}{|l|l|}
\hline $\begin{array}{l}\text { Parents' use of developmentally appropriate } \\
\text { involvement strategies }\end{array}$ & $\begin{array}{l}\text { Fit between parents' involvement actions \& } \\
\text { school expectations }\end{array}$ \\
\hline
\end{tabular}

Level 3

Mechanisms through which parental involvement influences child outcomes

\begin{tabular}{|l|l|l|}
\hline Modeling & Reinforcement & Instruction \\
\hline
\end{tabular}

Level 2

Mechanisms through which parental involvement influences child outcomes

\begin{tabular}{|l|l|l|}
\hline Modeling & Reinforcement & Instruction \\
\hline
\end{tabular}

Level 1

\begin{tabular}{|l|l|l|}
\hline \multicolumn{2}{|l|}{ Parent's basic involvement decision, influenced by } \\
\hline $\begin{array}{l}\text { Parent's construction of the } \\
\text { parental role }\end{array}$ & $\begin{array}{l}\text { Parent's sense of efficacy } \\
\text { for helping her/his children } \\
\text { succeed in school }\end{array}$ & $\begin{array}{l}\text { General invitations \& } \\
\text { demand for involvement } \\
\text { from child \& school }\end{array}$ \\
\hline
\end{tabular}

In creating and utilizing this model for parental involvement, Hoover-Dempsey and Sandler were seeking to answer the question, "Why do parents become involved in their children's education?" Through exploring this model, Hoover-Dempsey and Sandler found that parents' involvement decisions and choices are determined by several factors, including their own ideas and experiences, environmental demands, and involvement opportunities (1997).

Walker, Wilkins, Dallaire, Sandler, and Hoover-Dempsey (2005) further advanced the use of this model through a revised version that drew upon the findings and application of the first model. This revision combines the original ideas from Levels 1 and 2 and joined these into three overarching constructs that now make up Level 1 (Walker et al., 2005). Another difference in the 2005 revised model is the use of links that prompt possible relationships that exist between and within the levels. The original and revised versions of Level 1 and Level 2 are found in Figure 2 .

Figure 2. Original and Revised Model of Walker et al. (1997, 2005)

\section{Original (1997):}

Level 2

Parent's choice of involvement forms, influenced by: 
The Wingman Project

\begin{tabular}{|l|l|l|}
\hline $\begin{array}{l}\text { Specific domains of parent's } \\
\text { skill \& knowledge }\end{array}$ & $\begin{array}{l}\text { Mix of demands on total } \\
\text { parental time and energy } \\
\text { (family, employment) }\end{array}$ & $\begin{array}{l}\text { Specific invitations \& } \\
\text { demands for involvement } \\
\text { from child \& school }\end{array}$ \\
\hline
\end{tabular}

Level 1

\begin{tabular}{|l|l|l|}
\hline \multicolumn{2}{|l|}{ Parent's basic involvement decision, influenced by: } \\
$\begin{array}{l}\text { Parent's construction of the } \\
\text { parental role }\end{array}$ & $\begin{array}{l}\text { Parent's sense of efficacy } \\
\text { for helping her/his children } \\
\text { succeed in school }\end{array}$ & $\begin{array}{l}\text { General invitations \& } \\
\text { demand for involvement } \\
\text { from child \& school }\end{array}$ \\
\hline
\end{tabular}

\section{Revised (2005):}

Level $1 \& 2$

\begin{tabular}{|c|c|c|c|c|c|c|}
\hline \multicolumn{7}{|c|}{ Parents' Involvement Forms } \\
\hline \multicolumn{7}{|l|}{ contribute to } \\
\hline \multicolumn{2}{|c|}{$\begin{array}{l}\text { Parents' Motivational } \\
\text { Beliefs }\end{array}$} & \multicolumn{3}{|c|}{$\begin{array}{l}\text { Parents' Perceptions of Invitations for } \\
\text { Involvement from Others }\end{array}$} & \multicolumn{2}{|c|}{$\begin{array}{l}\text { Parents' Perceived Life } \\
\text { Context }\end{array}$} \\
\hline \multicolumn{2}{|l|}{ defined as: } & \multicolumn{3}{|l|}{ defined as: } & \multicolumn{2}{|c|}{ defined as: } \\
\hline $\begin{array}{l}\text { Parental } \\
\text { Role } \\
\text { Construction }\end{array}$ & $\begin{array}{l}\text { Parental } \\
\text { Self- } \\
\text { Efficacy }\end{array}$ & $\begin{array}{l}\text { Perceptions } \\
\text { of General } \\
\text { School } \\
\text { Invitations }\end{array}$ & $\begin{array}{l}\text { Perceptions } \\
\text { of Specific } \\
\text { Child } \\
\text { Invitations }\end{array}$ & $\begin{array}{l}\text { Perceptions } \\
\text { of Specific } \\
\text { Teacher } \\
\text { Invitations }\end{array}$ & $\begin{array}{l}\text { Self- } \\
\text { Perceived } \\
\text { Time and } \\
\text { Energy }\end{array}$ & $\begin{array}{l}\text { Self- } \\
\text { Perceived } \\
\text { Skills and } \\
\text { Knowledge }\end{array}$ \\
\hline
\end{tabular}

The 2005 revised version of Hoover-Dempsey and Sandler's model of the parental involvement process was utilized as the theoretical framework for this study. The focus of this study was exclusively on a portion of Level 1, motivational beliefs, and only from the vantage point of grandparents' involvement as an alternative to parents' involvement. Figure 3 shows my adaptation of the 2005 revised version of Hoover-Dempsey and Sandler's model for use in this study.

Figure 3. Author adaptation of Hoover-Dempsey \& Sandler revised model for grandparent involvement (2005)

Level 1: Focus on Motivational Beliefs

Grandparents' Involvement Forms 


\begin{tabular}{|l|l|}
\hline \multicolumn{2}{|l|}{ contribute to } \\
\hline $\begin{array}{l}\text { Grandparents' Motivational } \\
\text { Beliefs }\end{array}$ \\
\hline defined as: \\
\hline $\begin{array}{l}\text { Grandparent } \\
\text { Role } \\
\text { Construction }\end{array}$ & $\begin{array}{l}\text { Grandparent } \\
\text { Self-Efficacy }\end{array}$ \\
\hline
\end{tabular}

The proposed definition for grandparents' motivational beliefs includes grandparent role construction and grandparent self-efficacy. Role construction includes grandparent beliefs about child rearing, child development, and how the child's home should support the child's educational experiences. Additionally, this role construction is based on their own experiences as parents, thus enhancing their knowledge and influencing their beliefs. According to HooverDempsey et al. (2005), parents' knowledge can be enhanced through their involvement with individuals and groups related to schooling. In adapting Hoover-Dempsey and Sandler's (2005) model of the parental involvement process, this same understanding was applied to grandparents. Grandparents' knowledge about how and why to become involved with their grandchildren's education is influenced by experiences with schooling, as students or as parents. Grandparent self-efficacy indicates that grandparents make choices on their involvement based on what they think the outcomes are likely to produce. Grandparents who have experienced personal success and believe their actions will have a positive effect on their grandchild's education, are more likely to become involved. Both role construction and self-efficacy are influenced by the social forces that surround grandparents. This influence of social forces reflects the child's grandparents' involvement in school, lack of involvement in school, and the grandparents' role in child rearing.

\section{Findings}

How is school-grandparent communication influenced by the implementation of The Wingman Project in selected schools?

Through my inductive analysis, I generated three possible conclusions related to this research question. First, school-grandparent communications were influenced by creating a oneway communication method between the school and the grandparents. None of the three schools had a formal communication method in place designed to communicate with grandparents. So the implementation of The Wingman created an avenue of communication primarily from the schools to the grandparents regarding their grandchildren's education. It provided grandparents 
and other family members with a consistent and accessible publication that included: school events, academic information, and pictures. The school's role, since it was the source of The Wingman, seems to have been a facilitator of the communication.

Next, after reviewing the statements made by my participants and looking at the collective themes, it appears that The Wingman did very little to influence communication between the grandparent and the school sites. The grandparents rarely communicated back with the school. However, The Wingman did influence communication between the grandparents and their grandchildren and how the grandparents contributed to or participated in the grandchild's schooling. Through data collection I learned that grandparents used the content from The Wingman to hold conversations with their grandchildren.

My final finding related to research question number one is that as a result of The Wingman, grandparents felt much more included and knowledgeable about their grandchildren's school lives. The very idea of communication necessitates the idea that information, opinions, or thoughts are interchanged between individuals. Through The Wingman, an interchange of information between the school, grandparent, and grandchild was created.

In all three of my findings the establishment of one-way communication to grandparents increased communication between grandparents and grandchildren. Grandparents felt more included and knowledgeable. All three findings demonstrate that the greatest impact of The Wingman was this specific interchange of information. Because the school prioritized communicating in a regular and systematic way with grandparents, information was often interchanged between grandparents and grandchildren and sometimes exchanged between the school and the grandparents.

How was Hoover-Dempsey and Sandler's (2005) description of motivational beliefs established in regular participants of The Wingman Project?

a. How did The Wingman Project influence grandparent role construction in the education of their grandchildren?

b. How did The Wingman Project influence grandparent self-efficacy to become involved in their grandchildren's education?

To fully consider the findings related to my second research question, I chose first to consider each of the sub-questions and then combine my findings collectively in terms of the main question. My inductive analysis completed in the first phase of analysis provided some insight into each of my sub-questions. As I completed my deductive analysis of my data in the second phase of analysis, I gained additional understanding of each sub-question and a thorough understanding of my second main research question.

In drawing conclusions about my sub-question: How has The Wingman Project influenced grandparent role construction in the education of their grandchildren?, I observed that The Wingman had direct influence on role construction and supporting the grandchildren's educational experiences. In the area of role construction, the publication of The Wingman 
provided information, pictures, stories, and essentially a personalized tool to help grandparents stay connected, be informed, and be involved with their grandchildren. Of the six grandparents who were interviewed, four said that being involved in the day-to-day activities of their grandchildren was important. The Wingman focused on exactly those kinds of day-to-day topics at each school. In the same way, The Wingman provided specific ways that grandparents could support their grandchildren's educational experiences by keeping them informed about school events, providing dates and times to attend functions, and communicating any special requests from the school for the grandparents. The Wingman established and allowed the school to have the opportunity to contact grandparents and gave them ways to support the educational experiences of their grandchildren. In addition, one of my informants identified and described the different types of involvement and attitudes she noticed from either local or distant grandparents. While not specifically mentioned by the grandparents at this study's three school sites, the idea of different types of involvement and attitudes could be related to grandparents' perceptions of their roles in the grandchild's education. The Wingman allowed both local and distant grandparents to have access to school information that supported their roles in the grandchildren's school lives.

In drawing conclusions about my sub-question: How has The Wingman Project influenced grandparent self-efficacy to become involved in their grandchildren's education?, I observed that The Wingman had a direct influence by providing grandparents with more knowledge about their grandchild's educational experience. This additional information appeared to increase the grandparents' knowledge about what was happening at the school in a way that encouraged grandparents to talk to their student(s) about their school experiences. Grandparents may believe that conversations about school will be more effective and supportive of the child's learning if they have specific knowledge about what is happening at the school. Additionally, distant grandparents may be more inclined to call their grandchildren after specific events take place to ask them questions or inquire about the event. Grandparents could also plan to see their grandchildren during school breaks because they have access to the school's release dates.

Through the use of both my inductive analysis and deductive analysis I developed a clear understanding of my two sub-questions. In considering the analysis of each sub-question, I am now able to answer my second main research question: How is Hoover-Dempsey and Sandler's (2005) description of motivational beliefs established in regular participants of The Wingman Project?

Hoover-Dempsey and Sandler's (2005) description of motivational beliefs were fully established in Wingman participants. Hoover-Dempsey and Sandler (2005) identified role construction and self-efficacy as two of the factors that impact motivation and thus impact involvement. I discovered that these same factors impacted motivation and involvement of The Wingman participants. The Wingman enhanced the role construction of grandparents, the ability of grandparents to support the educational experiences, and grandparent knowledge of schooling developed their self-efficacy. Each of these factors supports the notion that recipients of The 
Wingman were likely motived to be involved in their grandchildren's education experiences. The unique design and delivery of The Wingman does suggest some possible limitations to understanding all grandparents' motivational beliefs. This study involved school-grandparent communication that utilized email as the contact method, and a possible limitation is that it excludes grandparents without email. Grandparents could choose to not use email as a communication method or socioeconomic barriers could prevent email use. Also, all of the interviewed grandparents were motived to receive The Wingman, so I didn't find out about the larger population of grandparents who may not be motivated at all to be involved with their grandchildren's educational experiences. For grandparents receiving The Wingman at the three research sites, the motivational factors of role construction and self-efficacy have been observed.

For each of the three pilot sites, I served as the creator and publisher for each monthly enewsletter. This responsibility as The Wingman creator led me to be in frequent communication with the lead administrators and also led me to ask questions or seek clarification when I was preparing editions of the e-newsletter. Due to my unique position as both the publisher of The Wingman and my role as the researcher, it is important to consider how this dual role may have impacted my study. My own knowledge of public school issues, my experiences as an educator and administrator, and my own beliefs about what content would be most interesting to grandparents influenced the content, organization, and structure of The Wingman. At each of the schools I attended multiple events to conduct observations and gain additional insight into the school's operation and family attendance at events. Over the course of the research project's timeframe, I developed professional relationships with school administrators and some other staff members. It was not uncommon for these school employees to visit with me at events and add extra detail that I would not have gathered from the observation alone. Throughout the study my primary role was always to be an observer first and to record information that would help me describe each school environment; however, since I did write each newsletter, I was also a participant in The Wingman. This dual role did influence my study by providing me with more knowledge and understanding about each school than if I had purely been an observer only of a communication method with grandparents. What, if any, impact my dual role may have had on others' interactions with or responses to The Wingman is unknown.

\section{Conclusions}

The findings from this study suggest that when schools make an effort to facilitate direct communication with grandparents, some grandparents are better prepared to support the educational experiences of their grandchildren. It is important to recognize that the schools in the research study truly did facilitate The Wingman by completing a few specific and easy steps. The schools allowed for paper invitations to be sent home with students, and they collected these forms. Next, either the lead administrator, secretary, or an involved teacher contributed pictures, upcoming events, and news stories to be included in The Wingman. These were submitted in a rough format, usually via email, and I created the newsletter design. I was responsible for the costs of the paper invitations, inputting the email addresses, and also distributing the e-newsletter 
each month. I think this is important to understand because it doesn't appear that The Wingman needs to be a publication that includes every possible detail about a school or creates a heavy burden on the school staff. As the researcher, I lived at least 45 miles away from each school and visited the schools only occasionally to deliver or retrieve paperwork. Yet I was able to create an e-newsletter that, based upon participant reports, was informative, enjoyable, and helpful to grandparents. Similarly, schools could recruit a parent, grandparent, or retired teacher to undertake this type of communication effort. With the investment of copies to recruit Wingman members and by training a volunteer to lead The Wingman effort, a school could have a personalized communication tool to reach grandparents and other family members at very little cost.

Another important understanding from my study and The Wingman is the knowledge that grandparents are an available and abundant resource, many of whom appear to want to be involved in their grandchildren's schools. As supported in my literature review, contemporary grandparents are healthier and have a longer life expectancy than ever before. Many grandparents desire to be involved in their grandchildren's education and by communicating with grandparents, schools support their involvement in the educational process. When considering these two factors, it seems almost negligent for public schools to miss out on the opportunity to communicate with and involve grandparents. I would also argue that the delivery method of The Wingman eliminates almost all cost to the school and makes email or another type of social media the most fiscally responsible and efficient way to communicate with all stakeholders about general school news.

A third finding from this research study is the hesitation of grandparents to participate in the data collection efforts related to this study. In my efforts to recruit interviews with grandparents, I sent the electronic survey to a total of 406 recipients; 33 grandparents responded, for a total of $8 \%$. Additionally, I made other exhaustive efforts at each school to recruit grandparents to complete interviews by inviting participants via the survey, via personal emails, and by a general invitation printed in The Wingman. Even with these great efforts, only six grandparents volunteered to complete the interview. Grandparents seemed resistant to participating in data collection efforts, an unexpected event given their existing engagement with The Wingman. Limited clues, such as the grandmother who stated she was not sure she had anything to offer, were available for understanding the seemingly widespread reluctance.

Other issues to consider in the conclusion of this study include the broader idea of the inclusion of grandparents in the education system, the modification of the Hoover-Dempsey \& Sandler's (2005) model, and the lack of communication from the grandparents to the schools. My research study only addressed one way of including grandparents in the three schools I studied. In actuality, there are many ways that grandparents could be included, such as serving as tutors, working as volunteers in libraries, offices, or the cafeteria, and being members of committees to organize school functions. As a school seeks out opportunities to inform grandparents of school happenings, the school may also find other ways to actively include grandparents. The modification of the Hoover-Dempsey and Sandler (2005) model of parental 
involvement is discussed in great detail in the following Implications section; however, it is important to note as a conclusion that both strengths and challenges in using this model were discovered during my study. Finally, the communication generated through The Wingman was entirely one-way communication that disseminated information from the school to the grandparents. Grandparents were not asked to suggest ideas for content or questions they would like to be addressed. In this way grandparents were not asked about their existing knowledge or how the school could expand their knowledge. The lead administrators and myself made the decisions about the e-newsletter content based on our experience in working with families.

These main understandings matter because in a time of unrest and financial strain for public schools, it is imperative that all available resources are used to support our nation's future leaders. By facilitating The Wingman, or a similar communication tool, and actively working to involve grandparents in schools, the educational process will be enhanced and students will benefit.

This study raises three important questions. First, the participants in this study were grandparents who were related to an enrolled student. How would non-related grandparents (in loco grandparentis) or other mature adults in a community react to being included in a communication effort from the area schools? Second, The Wingman in each of these schools was facilitated by a staff member or several staff members working together, and then published by myself. How could schools that rely on a volunteer to publish The Wingman ensure that the effort is maintained and successfully completed over a long time period? A final question is, How are grandparent role construction and grandparent self-efficacy related to each other? These questions will be further considered, within the context of this study, in the following paragraphs.

\section{How would non-related grandparents (in loco grandparentis) or other mature adults in a} community react to being included in a communication effort from the area schools?

The participants in this study were grandparents who were related to an enrolled student. If a grandparent lives a great distance from their own grandchildren, or doesn't have grandchildren, could he/she be a support resource for a local school? If local schools reached out to these in loco grandparentis or other mature adults in their neighborhood, they could potentially tap into an unconventional set of resources. Since The Wingman is delivered via email with very little cost to produce or publish, schools could communicate with a large number of possible pseudo-grandparents, family members, volunteers, or financial contributors. This question also suggests that possibly public schools as a whole need to find more consistent and frequent methods to communicate with all stakeholders. If businesses were informed about school events or needs, they may take an active role in supporting schools as well. An additional outcome of in loco grandparentis, other community members, and businesses becoming more involved in directly supporting the school may be an influence on voting behaviors. These local stakeholders are also voters whose participation in the voting process can lead to direct benefits for the school district. If voters have been regularly informed about school events, news, 
progress, and needs they may be better able to make informed decisions at the polls. Additionally, distant grandparents who may not be able to vote and impact local policy are still voters on the national level of consideration of educational policy.

How could schools that rely on a volunteer to publish The Wingman ensure that the effort is maintained and successfully completed over a long time period?

The Wingman in each of these schools was facilitated by a staff member, or several staff members working together, and then published by myself. At the original Wingman site, not included in the data set for this study, a parent was the original publisher of The Wingman, and then handed this responsibility over to a school staff member. With turnover in school staff, The Wingman effort was not maintained and now lies dormant. One idea to address this question is the possibility of paying a staff person or a parent to produce The Wingman. This solution would create an added cost to the relatively inexpensive communication effort, but it could support its longevity. In an attempt to rely on a volunteer to maintain the database and publish The Wingman, this job could be delegated to the Parent Teacher Association or another service organization within a school.

\section{How are grandparent role construction and grandparent self-efficacy related to each other?}

My study identified the need to further understand how grandparent role construction and grandparent self-efficacy are related to each other. For this study grandparent role construction was defined as what grandparents believe they should do in relation to their grandchildren's education and the educational process. Grandparent self-efficacy is defined in this study as the beliefs that grandparents have about the outcomes of their own involvement in their grandchildren's school lives. This definition is based on what they think their involvement will produce. One understanding that emerged from this study is that the grandparents who chose to receive The Wingman are probably grandparents who already had developed ideas about their role construction as a grandparent, and they might have already believed that being involved in their grandchildren's school lives was important. Additionally, if these grandparents believed their involvement would make a difference, they may make up the most efficacious of all grandparent groups. The dynamics of each family could also play an important role in the grandparents' role construction and self-efficacy. If a grandparent's relationship with his or her own son or daughter is healthy, they may be more inclined to participate in their grandchildren's lives in general, as well as in their school lives.

According to the extensive literature review I completed for this study, it is a firmly supported statement that parental involvement in schools is beneficial for the students. Furthermore, the limited amount of studies that exist concerning grandparent involvement point to a similar conclusion: that involvement benefits students. Simply put, when adults in the family care about a child's school experiences, invest time in helping them be successful, and value education, the outcomes for the students are more likely to be positive. 
In considering my findings from this research study, it appears that involving grandparents, even distant ones who have little access to the school, has the same potential for producing positive outcomes for students. If adults know about a child's school, help the child see the importance of school, and help the child believe that they can be successful, then the child is more likely to thrive. Also, grandparents are more likely to talk to their grandchild about the school and have a higher self-efficacy for what their involvement could produce when they have current relevant information pertaining to the school environment.

It appears that The Wingman has unearthed an affordable, sustainable, and powerful way to expand the number of people who may work together to support children's success in school. By utilizing email as a delivery method for important school information, the number of people who can be included in the communication loop with the school can be greatly increased, and we may provide opportunities for them to engage in conversations about school that might not otherwise have as much depth.

This study helped generate understanding about how grandparents can feel motivated to become involved in public schools, and it provided knowledge to contribute to current literature on family involvement in education. Furthermore, this study has helped to bridge the gap between what is known about how parents are motivated to become involved and how the grandparents in this study reacted to being involved via The Wingman.

\section{Implications}

The findings from this research study lead to implications in the areas of research, theory, and practice. In the section that follows I will report on what these findings suggest for research and imply for theory; I will then recommend steps for current practitioners. The implications for theory in terms of this study and future studies is particularly robust due to the nature of theory modification that I employed.

\section{Implications for Research}

As I conducted this research study several additional ideas for research studies presented themselves. First, an unexplored topic in this area includes the use of more instant forms of technological communication including text messaging, Twitter feeds and Facebook posts. A research study could be designed to explore the outcomes of more instant information on grandparents' motivational beliefs. Additionally, it is noted that more studies aimed at discovering the impact of all types of electronic communication between schools and families are needed to better understand these methods of communication.

Similar studies should be conducted at other schools that have a method of grandparent communication. Both technology based and non-technology based studies would add additional information. If both types of communication methods were studied, it could be better determined which type results in the most desirable effects. At the current research sites, research should be continued to explore long lasting experiences for schools, students, and grandparents. An additional research study could be conducted to see if a program focused on 
involving community members at large, not only grandparents, could result in similar experiences for the school and adults. Additional research could also focus on social justice by considering the idea that we could strengthen the educational system in America by tapping into retired adults and/or grandparents.

In relation to my theoretical framework I only explored one aspect of Hoover-Dempsey and Sandler's (2005) model. Further research could focus on other components of motivation. For instance, Grandparents' Perceptions of Invitations for Involvement from Other and Grandparents' Perceived Life Context are two other broad areas that impact motivation for involvement and could be studied. Also, in these two areas, the grandparent's relationship with their own children, the grandchildren's parents, would be an interesting component to measure. How do grandparents perceive invitations for involvement from the child's parents? How is the grandparent perception of their relationships with the grandchildren and parents tied to their life context?

\section{Implications for Theory}

As I have explained in several other areas throughout my study, I chose to utilize HooverDempsey and Sandler's (2005) model of the parental involvement process as the theoretical framework. I chose this model because it focuses on explaining the motivation for, and process of, parental involvement. In making the decision to use Hoover-Dempsey and Sandler's (2005) model, I knew that it would require modification in order to be used as a lens for my study. My study focuses on communication with grandparents and grandparents' motivational beliefs. There have been several observable strengths with using the model. First, the model has been in existence for 17 years in the original form, and it has been used in numerous studies by HooverDempsey, Sandler, and others. I believe the longevity of the framework's existence adds to its credibility. Second, the model is extensive in its exploration of factors that contribute to parent involvement. I chose to focus on motivational beliefs, but the model also includes specific definitions of how parents perceive invitations from others and how the parents' perceived life context impacts involvement.

In addition to the observable strengths, there are also weaknesses associated with the Hoover-Dempsey and Sandler (2005) model of the parental involvement process that impacted its usefulness in my study. First, the most obvious weakness is that the model and the studies that utilize this model do not offer any inclusion or explanation for grandparent involvement. I did not find any information during my literature review that offered an accepted modification of this model for grandparents. This weakness required that I use the presented definitions of role construction and self-efficacy and interpret those in relation to grandparents. In completing my deductive analysis I had trouble distinguishing between pieces of my data that explained how grandparents thought the child's home should support the educational experiences and how grandparents thought they should support the child's educational experiences. The model identifies the home as the child's home; however, grandparents spoke of their support as if it was part of the home. 
Another weakness of the Hoover-Dempsey and Sandler (2005) model of the parental involvement process in relation to my study was that it does not distinguish between resident and nonresident parents or, in my study, near or distant grandparents. Role construction is likely to be influenced by how often and in what capacity a parent or a grandparent interacts with the child. The model does not provide insight into how nonresidential parents or distant grandparents might use other avenues to construct their roles as an important figure in the child's educational experiences.

I found using the Hoover-Dempsey and Sandler (2005) model an interesting experience in expanding current application of theory. Essentially, I was using my data to determine which aspects of the accepted theory seem to hold true and which aspects need more serious modification to work with grandparent involvement. Of course, this exploration was regarding only a small portion of the entire theory and would need to be replicated many times to establish a final line of thought regarding adaption to grandparents.

During my deductive analysis I worked to interpret my data in terms of the presented definitions of role construction and self-efficacy. Within each definition, I categorized data as supporting the definition, conflicting with the definition, or presenting an idea not currently included in the definition. In the area of role construction, three ideas not currently included in the definition presented themselves as other emerging realities. These three ideas were: that grandparents associate their grandchildren with a great sense of enjoyment and love, grandparents are interested and supportive of all kids, and grandparents show an abundance of appreciation for information provided by The Wingman. In the area of self-efficacy there was one other emerging reality: the need for specific ways for grandparents to contribute.

\section{Implications for Practitioners}

The implications for current practitioners are in a sense very simple, yet have the potential to produce profound effects on the school environment. The Wingman has been shown to be beneficial in involving grandparents in their grandchildren's educational experiences. In some instances involvement has included being directly involved at the school or providing donations that fulfill school needs. Grandparent involvement also manifests itself in the form of grandparent-grandchild communication that supports the child's success in school.

In terms of donations to the school and financial support there are two specific understandings that should influence practitioners. First, at the original pilot site, not included in this study, there were numerous examples of grandparents donating needed items or providing monetary donations to buy needed items. These donations were a result of specific requests being published in The Wingman, and grandparents being motivated to help meet the need. In one story, a grandmother actually contacted The Wingman publisher in order to facilitate her ordering a needed item and having it shipped to the school from the site of her vacation. This story, and others like it, demonstrates that when needs were presented to grandparents they were eager to contribute. In the three pilot sites used for this study, there were very few broad requests published in The Wingman, so there were not as many opportunities for grandparents to 
donate. Also, the school data collection of such donations was not accurately completed at the three sites.

A second important understanding for practitioners is that by communicating with grandparents, the school is developing a constituency of financially secure and committed community members. These mature community members may remain loyal to the school over a long period of time. This implies that a school could actually be better poised to recruit volunteers, secure donations, and provide for needs within the school, especially in economic downturns.

In conclusion, the simple, yet profound, recommendation for practicing teachers and administrators is to develop a consistent and cost-effective method for communicating with as many grandparents as possible. Additionally, practitioners should provide specific ways that the readers can contribute to the school either through service or donation. Evidence from this study and the original pilot site indicate that grandparents are eager to engage with the educational system.

\section{Acknowledgments}

I would like to acknowledge the contributions of Dr. Kerri S. Kearney, Associate Professor at Oklahoma State University, to this research study. Dr. Kearney was the original creator of The Wingman at the pilot site and served as my dissertation advisor while I conducted The Wingman study at three additional schools. The design, data analysis, and findings of this study were greatly supported by Dr. Kearney's expertise and dedication to assisting my research efforts.

\section{References}

Creswell, J. W. (1998). Qualitative inquiry and research design: Choosing among five traditions. Thousand Oaks, CA: Sage Publications.

Epstein, J. L. \& Van Voorhis, F.L. (2010). School counselors' roles in developing partnerships with families and communities for student success. Professional School Counseling, 14(1), 1-14.

Hoover-Dempsey, K., Bassler, O., \& Brissie, J. (1992). Explorations in parent-school relations. Journal of Educational Research, 85(5), 287-294. 
Hoover-Dempsey, K., \& Sandler, H. (1997). Why do parents become involved in their children's education? Review of Educational Research, 67(1), 3-42.

Hoover-Dempsey, K.V., \& Sandler, H.M. (2005). Final Performance Report for OERI Grant \#R305T010673: The Social Context of Parental Involvement: A Path to Enhanced Achievement. Presented to Project Monitor, Institute of Education Sciences, U.S. Department of Education, March 22, 2005.

Hoover-Dempsey, K., Walker, J., Sandler, H., Whetsel, D., Green, C., Wilkins, A., \& Closson, K. (2005). Why do parents become involved? Research findings and implications. Elementary School Journal, 106(2), 105-130.

Mutch C. \& Collins, C. (2012). Partners in learning: Schools' engagement with parents, families, and communities in New Zealand. School Community Journal, 22(1), 167-187.

Reynolds, G.P., Wright, J.V., \& Beale, B. (2003). The roles of grandparents in educating today's children. Journal of Instructional Psychology, 30(4), 316-325.

Sear, R. \& Coall, D. (2011). How much does family matter? Cooperative breeding and the demographic transition. Population and Development Review, 17, 81-112.

Spudich, D. \& Spudich, C. (2010). Welcoming intergenerational communication and senior citizen volunteers in schools. Improving Schools, 13(2), 133-142.

Strom, R.D. \& Strom, S.K. (1995). Intergenerational learning: Grandparents in the schools. Educational Gerontology, 21(4), 321-335.

Tanskanen, A.O. \& Danielsbacka, M. (2012). Beneficial effects of grandparental involvement vary by lineage in the UK. Personality and Individual Differences, 53, 985-988.

Tinker Air Force Base. (2011). Virtual Wingman para. 1. Retrieved from http://www.tinker.af.mil/virtualwingman/index.asp

Walker, J.M.W., Wilkins, A.S., Dallaire, J.R., Sandler, H.M., \& Hoover-Dempsey, K.V. (2005). Parental involvement: Model revision through scale development. The Elementary School Journal, 106(2), 85-104.

Yorgason, J.B., Padilla-Walker, L., \& Jackson, J. (2011). Nonresidential grandparents' emotional and financial involvement in relation to early adolescent grandchild outcomes. Journal of Research on Adolescence, 21(3), 552-558. 